
РЕЦИДИВА ПРЕСТУПЛЕНИЙ

\author{
Belyaeva I.M. , Zubenko I.A.
}

\title{
SOME QUESTIONS OF DETERMINING THE RELAPSE OF CRIMES
}

В статье на основании данных официальной статистики обосновывается необходимость глубокого изучения уголовно-правового рецидива в контексте реализации уголовной политики, направленной на противодействие рецидивной преступности. Не заостряя внимание на самом понятии рецидива преступлений и его видах, которые закреплены в статье 18 УК РФ, авторы анализируют конкретные примеры из судебной практики, определяя типичные ошибки в установлении судами рецидива преступлений, либо в установлении вида рецидива, что существенно отражается на качестве приговоров, их справедливости. Акцентируется внимание на взаимосвязи в применении статей 18, 63, 68 УК РФ при назначении наказания.

Ключевые слова: рецидивная преступность, рецидив преступлений, назначение наказания при рецидиве преступлений.

The article, based on official statistics, justifies the need for in-depth study of criminal recidivism in the context of the implementation of criminal policy aimed at combating recidivism. Without focusing on the very concept of recidivism and its types, which are enshrined in Article 18 of the Criminal Code of the Russian Federation, the authors analyze specific examples from judicial practice, identifying typical errors in the establishment of recidivism by courts or in the establishment of the type of recidivism, which significantly affects the quality of sentences and their fairness. The focus is on the relationship in the application of Article 18 of the Criminal Code of the Russian Federation. Articles 18, 63, 68 of the Criminal Code of the Russian Federation in the imposition of punishment.

Keywords: recidivism, recurrence of crimes, punishment in case of recidivism.

Важным направлением уголовной политики в современной России является стремление государства к снижению уровня рецидивной преступности. К сожалению, невозможно сказать о том, что уровень рецидивной преступности снижается [1]. На первый взгляд, мы можем отметить положительную динамику уменьшение абсолютных показателей о лицах, ранее совершавших преступления:

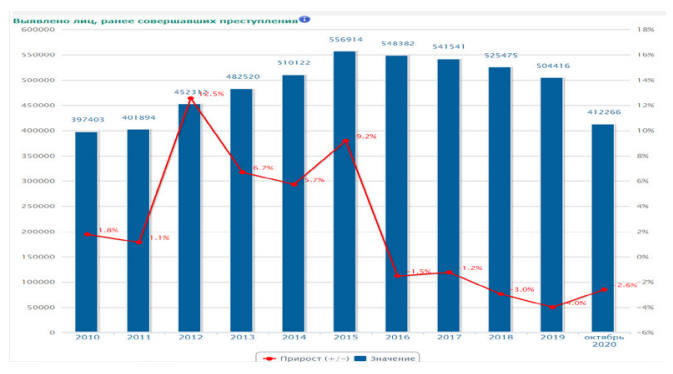

Но эти данные невозможно оценить в разрыве с информацией об общем количестве выявленных лиц, совершивших преступление:

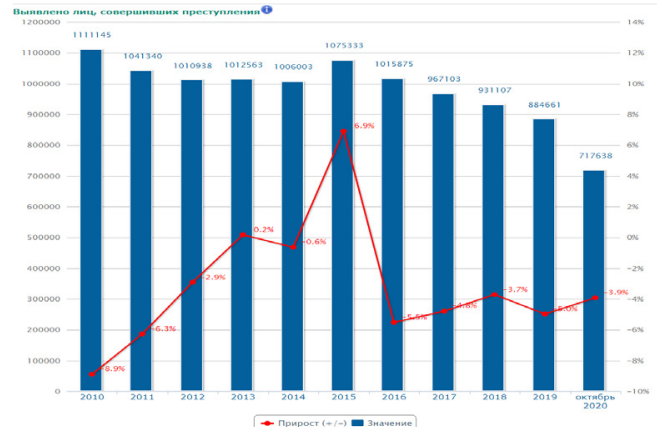

Соотношение данных, приведенных в этих диаграммах, однозначно свидетельствует о том, что количество лиц, ранее совершавших преступления, в общем 
объеме выявленных лиц, совершивших преступления, сокращается только в абсолютном выражении, но в относительных величинах положение практически не меняется, и уровень фактического рецидива остается высоким. Уменьшение количественного абсолютного показателя «рецидивистов» связано с сокращением выявления общего количества лиц, совершивших преступления, что, в свою очередь, вытекает из современных особенностей структуры населения России: тельном количестве лиц, привлекаемых к уголовной ответственности, имеющих не просто криминальный опыт, а судимость, образующий рецидив в смысле ст. 18 УК РФ [4].

Возможно, данные выводы слишком линейны и, однозначно, вопрос о снижении уровня рецидивной преступности требует более глубокого изучения не только с этих позиций. Но мы и не ставим задачу глубокого анализа динамики рецидивной преступности. Для нас важно, что

\begin{tabular}{|c|c|c|c|c|c|c|c|c|}
\hline & 2014 & 2015 & 2016 & 2017 & 2018 & 2019 & 2020 & \\
\hline $\begin{array}{l}\text { Все население } \\
\text { тыс.чел. }\end{array}$ & 143667 & 146267 & 146545 & 146804 & 146880 & 146781 & 146749 & 4 \\
\hline \multicolumn{9}{|l|}{$\begin{array}{l}\text { в том числе в } \\
\text { возрясте, лет. }\end{array}$} \\
\hline $0-4$ & 8898 & 9262 & 9512 & 8582 & 9347 & 9032 & 8579 & $y$ \\
\hline $5-8$ & 7862 & 8004 & 8218 & 8558 & 8873 & 9085 & 8309 & $r$ \\
\hline $10-14$ & 6823 & 7128 & 7254 & 7408 & 7598 & 7825 & 8049 & $r$ \\
\hline $15-19$ & 6856 & 6829 & 6731 & 6890 & 6816 & 6947 & 7161 & $r$ \\
\hline $20-24$ & 9971 & 9293 & 8445 & 7828 & 7336 & 7114 & 6889 & 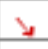 \\
\hline $25-29$ & 12522 & 12820 & 12412 & 11879 & 11120 & 10222 & 9427 & 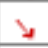 \\
\hline $30-34$ & 11660 & 12092 & 12219 & 12537 & 12786 & 12718 & 12833 & 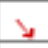 \\
\hline $35-39$ & 10814 & 10884 & 11088 & 11194 & 11425 & 11735 & 12003 & $r$ \\
\hline $40-44$ & 9750 & 10122 & 10220 & 10381 & 10453 & 10594 & 10708 & 4 \\
\hline $45-48$ & 9187 & 9140 & 9193 & 9280 & 9499 & 9874 & 9896 & $r$ \\
\hline $50-54$ & 11184 & 10957 & 10356 & 9835 & 9372 & 9021 & 8846 & 4 \\
\hline $55-59$ & 10634 & 10873 & 11093 & 11155 & 11049 & 10811 & 10443 & 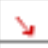 \\
\hline $60-64$ & 8849 & 9260 & 9445 & 9810 & 9783 & 10027 & 10106 & $\pi$ \\
\hline $85-69$ & 5269 & 6428 & 7263 & 7837 & 7937 & 8179 & 8339 & $r$ \\
\hline 70 и более & 13587 & 13377 & 13086 & 13230 & 13506 & 13797 & 14381 & $\lambda$ \\
\hline \multicolumn{9}{|c|}{ Из общей численности - население в возрасте: } \\
\hline $\begin{array}{c}\text { молоке } \\
\text { трудоспособного }\end{array}$ & 24717 & 25689 & 26380 & 26895 & 27254 & 27430 & 27442 & \\
\hline трудоспособном & 85182 & 85415 & 84189 & 83224 & 82284 & 81382 & 82878 & \\
\hline $\begin{array}{c}\text { стярше } \\
\text { трудоспособного }\end{array}$ & 33788 & 35183 & 35986 & 36885 & 37362 & 37989 & 36629 & \\
\hline
\end{tabular}

Как видно из данных официальной статистики о возрастном составе российского населения [2], в динамике отмечается уменьшение населения возрастных групп, обладающих наиболее выраженной криминальной активностью. Это позволяет говорить о том, что количественное уменьшение этих групп населения приводит к сокращению количественных показателей лиц, совершивших преступления, и, соответственно, количественно уменьшается и сегмент «рецидивиСтов».

Показательна информация официальной статистики и относительно уголовноправового рецидива, который на протяжении последних лет также остается практически неизменным. Приведенные ниже данные (период с января по октябрь 2020 года) [3] свидетельствуют о значи- вопросы рецидива по-прежнему остаются актуальными исходя из уровня преступности данного вида.

Таким образом, обращение к вопросу о рецидиве преступлений в контексте применения норм уголовного законодательства при квалификации преступлений и при назначении наказания вполне актуален, несмотря на богатый опыт правоприменительной практики в данной сфере. Даже качественное обобщение судебной практики о назначении наказания при наличии рецидива преступлений и вполне определенные правовые позиции Верховного суда Российской Федерации по данному вопросу не снимают проблем в правоприменении [5, п.п. 45-49].

Статья 18 УК РФ дает определение понятия рецидива, классифицирует его на виды. Не будем повторять эти законода- 


\begin{tabular}{|c|c|c|c|c|c|c|}
\hline & \multirow[b]{2}{*}{ ecero } & \multirow[b]{2}{*}{ Aneverea s } & \multirow{2}{*}{ 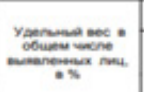 } & \multicolumn{3}{|c|}{ 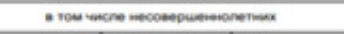 } \\
\hline & & & & ecero & Anoweres : & 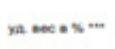 \\
\hline Выяалено лиц. совершинаших преступления & 717638 & $-3,9$ & & 27156 & $-11,2$ & \\
\hline \multicolumn{7}{|l|}{ a mon yucne: } \\
\hline несовершеннолетиях & 27156 & $-11,2$ & 3.8 & & & \\
\hline женцияе & 114904 & $-4,8$ & 16.0 & & & \\
\hline масиихся, студевтов & 28633 & $-14,2$ & 4.0 & 19411 & $-14,8$ & 71,5 \\
\hline 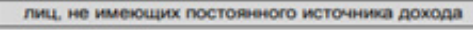 & 460163 & $-3,7$ & 64,1 & 407 & $-79,4$ & 1,5 \\
\hline безрасотных & 4559 & 21,1 & 0,6 & 21 & $-47,5$ & 0,1 \\
\hline ранее совериавших преступпеняия & 412266 & $-2,6$ & 57,4 & 6944 & -7.8 & 25,6 \\
\hline \multicolumn{7}{|l|}{ W3 $M U x^{\prime}$} \\
\hline равее судимыхх за преступпения . & 214504 & $-2,7$ & 52,0 & 2439 & $-14,5$ & 9,0 \\
\hline 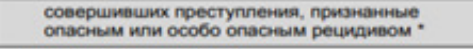 & 16149 & $-1,7$ & 3.9 & o & - & 0 \\
\hline s cocrabe rpynn ( scex) & 91433 & $-7,5$ & 12.7 & 12654 & -11.2 & 46.6 \\
\hline \multicolumn{7}{|l|}{ an mucre: } \\
\hline $\begin{array}{l}\text { организоеанной группы пибо преступного } \\
\text { сообедестеа :- }\end{array}$ & 8454 & -0.2 & 9.2 & 61 & $-27,4$ & 0.2 \\
\hline \multicolumn{7}{|l|}{ - cocmornuz anbanenus: } \\
\hline ankoronanoro & 245484 & $-3,1$ & 34.2 & 3283 & -8.4 & 12,1 \\
\hline наржотинесккого & 6053 & -15.8 & 0.8 & 81 & -3.6 & 0.3 \\
\hline
\end{tabular}

тельные установления, только подчеркнем, что они основаны на наличии судимости за ранее совершенные умышленные преступления, их категории, а также на виде назначенного ранее наказания и месте его отбывания.

Традиционно принято считать, что наличие рецидива имеет непосредственное отношение исключительно к институту назначения наказания. Как представляется, в связи с дополнением статей 131 и 132 УК РФ частью 5 [6], современное российское уголовное право получило «старый» подход к специальному рецидиву в «новой» формулировке и более ограниченного спектра действия. Советское уголовное право на протяжении многих лет достаточно успешно использовало данный институт (например, в преступлениях против социалистической, личной собственности, против жизни и т.д.) [7], ориентированный именно на противодействие рецидивной преступности и [8].

Как представляется, закрепление особенностей субъекта в качестве особо квалифицирующего признака насильственных преступлений против половой неприкосновенности фиксирует именно признаки специального рецидива - «Деяние, предусмотренное пунктом «б» части четвертой настоящей статьи (в отношении потерпевшей, не достигшей четырнадцатилетнего возраста в ст. 131 УК РФ; в ст. 132 УК РФ - в отношении лица, не достигшего четырнадцатилетнего возраста прим. авторов), совершенное лицом, имеющим судимость за ранее совершенное преступление против половой неприкосновенности несовершеннолетнего».

Представляется, что при назначении наказания при совершении преступлений, предусмотренных ч. 5 ст. 131 или ч. 5 ст. 132 УК РФ должно действовать правило, закрепленное в ч. 2 ст. 63 УК РФ «Если отягчающее обстоятельство предусмотрено соответствующей статьей Особенной части настоящего Кодекса в качестве признака преступления, оно само по себе не может повторно учитываться при назначении наказания». Именно таким образом формируется судебная практика по данным преступлениям.

Применительно к установлению рецидива в процессе назначения наказания стоит отметить, что именно с него законодатель начинает формировать исчерпывающий перечень обстоятельств, отягчающих наказание.

На первый взгляд, при назначении наказания при наличии рецидива преступлений мы видим существенное противоречие: с одной стороны, суд должен учесть его в качестве отягчающего наказание обстоятельства, с другой - правила назначения наказания, закрепленные в ст. 68 УК РФ устанавливают минимальный предел наказания, которое может быть назначено при наличии рецидива. Возникает вопрос наличия конкуренции норм, регулирующих одно и то же общественное отношение, устанавливающих правила разрешения одной и той же ситуации. На наш взгляд, конкуренция между нормами статей 18, 63 и 68 УК РФ отсутствует, поскольку каждая из них выполняет свою роль, не конкурируя, а дополняя друг друга. Так, ст. 18 УК РФ определяет понятие рецидива и его виды как формы множественности преступлений, ст. 63 УК РФ фиксирует рецидив как отягчающее

\section{5}

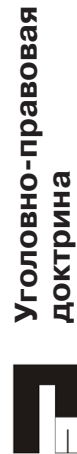


обстоятельство, которое должно быть учтено при назначении наказания, а механизм непосредственно назначения наказания (при установлении обстоятельств, указанных в ст.ст. 18 и 63 УК РФ) сформирован в ст. 68 УК РФ в виде специального правила. Тем не менее, иногда правоприменители допускают ошибки на одном из этапов анализа и уголовно-правовой оценки рецидива.

Так, например [9], суд первой инстанции в обвинительном приговоре в отношении группы лиц совершившей по предварительному сговору преступление, предусмотренное ч. 3 ст. 162 УК РФ, одному из соучастников назначил наказание по правилам ст. 68 УК РФ в виде лишения свободы с отбыванием наказания в исправительной колонии особого режима, установив наличие в действиях Д. особо опасного рецидива. Из материалов дела установлено, что Д. был осужден 14.04.1995 г. по п.п. «а», «е», «3», «н» ст. 102, п.п. «а», «б», «В», «Д» ч. 2 ст. 146 УК РСФСР к 15 годам лишения свободы, приговор вступил в законную силу 12.09.1996 г., постановлением районного суда от 27.05.2005 г. Д. был освобожден 06.06.2005 г. условно-досрочно на срок 3 года 10 мес. 20 дней. В последующем неотбытое наказание вошло в совокупность приговоров от 04.06.2010 г. и от 09.02.2011 г., судимости по которым погашены. Постановлением районного суда от 16.05.2014 г. Д. 27.05.2014 г. освобожден условно-досрочно на 07 мес. 06 дней. Выражая несогласие с приговором, прокурор в апелляционном представлении указал, что имеет место неправильное применение уголовного закона, поскольку вводная часть приговора в отношении Д. содержит сведения о судимостях, которые в силу ст. 86 УК РФ фактически погашены. Кроме того, в силу ст. 7.1 УК РСФСР и ст. 18 УК РФ в действиях Д. имеет место опасный, а не особо опасный рецидив, как это указано в приговоре суда первой инстанции, в связи с чем Д. также неверно определен вид исправительной колонии для отбывания наказания в виде лишения свободы. Суд апелляционной инстанции доводы прокурора об установлении иного вида рецидива нашел убедительными, руководствуясь тем, что ст.ст. 102, 146 УК РСФСР в силу ст. 7.1 этого же кодекса относились к категории тяжких. Исходя как из положений УК РФ, так и УК РСФСР, срок погашения судимости в рамках толкования положений ст. 57 УК РСФСР, ст. 86 УК РФ, срок погашения судимости за совершенные преступления считается не истекшим. При указанных обстоятельствах, в соответствии со ст. 18 УК РФ, в действиях осужденного Д. усматривается наличие рецидива преступлений, который в соответствии с ч. 2 ст. 18 УК РФ является опасным. Как следствие, в силу п. «В» 4. 1 ст. 58 УК РФ, апелляционная инстанция изменила вид исправительного учреждения на исправительную колонию строгого режима. Кроме того, были внесены изменения в вводную часть приговора в отношении Д. - исключены сведения о его погашенных судимостях.

Интересная ситуация сложилась при рассмотрении апелляционной жалобы, принесенной осужденным П. [10]. В обвинительном приговоре районного суда отражены следующие судимости П.: 1) 04.10.2016 г. осужден по п. «в» ч. 2 ст. 158, ч. 1 ст. 166 УК РФ к 03 годам лишения свободы; 2) 19.10.2016 г. осужден по ч. 1 ст. 161 УК РФ к 01 году 10 мес. лишения свободы; 3) 22.12.2016 г. осужден по п. «а» ч. 2 ст. 116 УК РФ с применением ч. 5 ст. 69 УК РФ к 03 годам 05 мес. лишения свободы; 4) 17.02.2017 г осужден по ч. 1 ст. 160, ч. 1 ст. 161 УК РФ применением ч. 5 ст. 69 УК РФ к 03 годам 08 мес. лишения свободы; 5) 03.04.2017 г. осужден по ч. 1 ст. 161, п. «Г» ч. 2 с. 161 УК РФ применением ч. 5 ст. 69 УК РФ к 04 годам 06 мес. лишения свободы; 6) 26.04.2017 г. осужден по ч. 1 ст. 161, п. «Г» ч. 2 с. 161 УК РФ применением ч. 5 ст. 69 УК РФ к 05 годам лишения свободы, 06.03.2019 постановлением районного суда неотбытая часть наказания заменена ограничением свободы на срок 02 года 05 мес. 17 дней; 23.06.2020 г. осужден по ч. 2 ст. 159 УК РФ (два события преступления) к 02 годам лишения свободы за каждое преступление, по ч. 3 ст. 159 УК РФ к 02 годам 06 мес. лишения свободы, на основании ч. 3 ст. 69 УК РФ путем частичного сложения назначено наказание в виде лишения свободы сроком 04 года, на основании ст.ст. 70, 71 УК РФ по совокупности преступлений присоединена неотбытая часть по приговору от 26.04.2017 г., окончательно наказание назначено наказание в виде лишения свободы сроком на 04 года 03 мес. с отбыванием наказания в исправительной колонии строгого режима. Вид рецидива судом первой инстанции был определен по всей совокупности преступлений как опасный. Апелляционная инстанция в своем определении отметила, что П. совершены два преступления, предусмотренные ч. 2 ст. 159 УК РФ и применительно к ним рецидив определяется в соответствии с ч. 1 ст. 18 УК РФ, а применительно к преступлению, предусмотренному ч. 3 ст. 159 УК РФ - в соответствии с п. 
«б» ч. 2 ст. 18 УК РФ, как опасный и изменила приговор в указанной части ввиду неправильного применения уголовного закона. Кроме того, из водной части приговора было исключено указание на судимости П. по приговорам от 18.05.2009 г., 10.11.2015 г. , 08.05.2015 г.

Ошибка в применении ст. 18 УК РФ при определении рецидива была допущена при постановлении обвинительного приговора по уголовному делу в отношении C. [11]. Так, районный суд, решая вопрос о наличии рецидива в действия С., ссылался на судимости по приговорам от 06.06.2013 г. по ч. 1 ст. 228 УК РФ и от 24.07.2013 г. по ч. 2 ст. 228 УКРФ. В апелляционном представлении государственный обвинитель указал, что согласно п. «а» 4. 4 ст. 18 УК РФ при признании рецидива преступлений не учитываются судимости за умышленные преступления небольшой тяжести и указание суда первой инстанции о том, что рецидив образует судимость по приговору 06.06.2013 г. не соответствует уголовному закону. Апелляционная инстанция с доводами государственного обвинителя согласилась, исключив из описательно-мотивировочной части приговора в отношении С. указание об образовании рецидива преступлений приговором от 06.06.2013 г.

Схожая ситуация имела место при определении судом первой инстанции опасного рецидива в действиях Т. [12]. При постановлении обвинительного приговора 20.02.2019 г. по п. «Г» ч. 2 ст. 161 УК РФ (три преступных деяния) районный суд принял во внимание наличие судимостей Т. по приговорам: 1) от 20.11.2015 г. по ч. 1 ст. 161 УК РФ (три преступных деяния); 2) от 01.12.2015 г. по ч. 1 ст. 161 УК РФ; 3) от 29.11.2016 г. по ч. 1 ст. 161 УК РФ; от 18.02.2019 г. по ч. 1 ст. 161 УК РФ и установил в действиях Т. опасный рецидив. В апелляционном представлении прокурор выразил несогласие с приговором в части наличия в действиях осужденного опасного рецидива, мотивируя свое мнение тем, что Т. ранее судим за преступления средней тяжести. Апелляционная инстанция с доводами прокурора согласилась и изменила приговор в части - указав, что два преступления, предусмотренные п. «Г» ч. 2 ст. 161 УК РФ совершены Т. в условиях простого рецидива вместо опасного, сократив срок лишения свободы по каждому из этих преступлений.

Аналогичную ошибку суд первой инстанции допустил при вынесении обвинительного приговора в отношении Б. [13], установив рецидив при наличии не снятой и непогашенной судимости за совершение преступления, предусмотренного ч. 1 ст. 112 УК РФ, которое в соответствии со ст. 15 УК РФ относится к категории преступлений небольшой тяжести. Апелляционная инстанция исключила из описательно-мотивировочной части приговора указание на наличие у Б. рецидива преступлений и признание его отягчающим обстоятельством, смягчив наказание.

Как видно из приведенных примеров, судебная практика знает случаи неправильного определения наличия рецидива преступлений или его видов в действиях подсудимого и, как следствие, допускает ошибки в применении специальных правил назначения наказания. Возможно, такая ситуация возникает в связи с особенностями толкования уголовно-правовой нормы, закрепленной в ст. 18 УК РФ, слишком сложной по конструкции.

В данной работе мы попытались обосновать необходимость глубокого изучения института рецидива преступлений, актуальность такой работы с учетом современного состояния рецидивной преступности. Полагаем, что анализ типичных ошибок, которые пусть редко, но допускаются судами первой инстанции при определении рецидива преступлений или его видов, поможет правоприменителю верно оценивать наличие или отсутствие данной формы множественности преступлений и, как итог - сократит апелляционное обжалование приговоров как несправедливых.

\section{Литература}

1. Портал правовой статистики // http://crimestat.ru/

2. МВД РФ. Статистика и аналитика // https://xn--b1aew.xn--p1ai/reports/ item/21933965

3. Федеральная служба государственной статистики // https://rosstat.gov.ru/ folder/12781

4. Уголовный Кодекс Российской Федерации от 13 июня 1996 г. № 63-Ф3 // Собрание законодательства РФ. - 17.06.1996 г. - № 25. - ст. 2954 // http://ips. pravo.gov.ru:8080/document/232/

5. Постановление Пленума Верховного Суда Российской Федерации от 22 декабря 2015 года № 58 «О практике назначения судами Российской Федерации уголовного наказания» (с изменениями, внесенными постановлениями 
Пленума от 29 ноября 2016 г. № 56, от 18 декабря 2018 г. № 43) // http://www. supcourt.ru/documents/own/8470/

6. Федеральный закон от 29 февраля 2012 г. № 14-Ф3 «О внесении изменений в Уголовный кодекс Российской Федерации и отдельные законодательные акты Российской Федерации в целях усиления ответственности за преступления сексуального характера, совершенные в отношении несовершеннолетних» // https://rg.ru/2012/03/02/neswovershennoletnye-dok.html

7. Уголовный кодекс РСФСР от 27 октября 1960 г. (УК РСФСР) (с изменениями и дополнениями) (утратил силу) // https://base.garant.ru/10107062/

8. Свинкин А.И., Юшков Ю.Н. Особо опасный рецидив как квалифицирующий признак преступления // Известия высших учебных заведений. Правоведение. - 1975. - № 5. - C.92-100 // https://www.elibrary.ru/item.asp?id=24218252 9. Уголовное дело № 10-432/2020 // Архив Челябинского областного суда.

10. Уголовное дело № 10-4857/2020 // Архив Челябинского областного суда.

11. Уголовное дело № 10-1408/2019 // Архив Челябинского областного суда.

12. Уголовное дело № 10-1694/2019 // Архив Челябинского областного суда.

13. Уголовное дело № 10-4862/2016 // Архив Челябинского областного суда.

\section{References}

1. Portal pravovoj statistiki // http://crimestat.ru/

2. MVD RF. Statistika i analitika // https://xn--b1aew.xn--p1ai/reports/ item/21933965

3. Federal’naya sluzhba gosudarstvennoj statistiki // https://rosstat.gov.ru/ folder/12781

4. Ugolovny j Kodeks Rossijskoj Federaczii ot 13 iyunya 1996 g. \# 63-FZ // Sobranie zakonodatel'stva RF. - 17.06.1996 g. - \# 25. - st. 2954 // http://ips.pravo.gov. ru:8080/document/232/

5. Postanovlenie Plenuma Verkhovnogo Suda Rossijskoj Federaczii ot 22 dekabrya 2015 goda \# 58 «O praktike naznacheniya sudami Rossijskoj Federaczii ugolovnogo nakazaniya» (s izmeneniyami, vnesenny`mi postanovleniyami Plenuma ot 29 noyabrya 2016 g. \# 56, ot 18 dekabrya 2018 g. \# 43) // http://www.supcourt.ru/ documents/own/8470/

6. Federal'ny`j zakon ot 29 fevralya 2012 g. \# 14-FZ «O vnesenii izmenenij v Ugolovny`j kodeks Rossijskoj Federaczii i otdel 'ny`e zakonodatel 'ny e akty” Rossijskoj Federaczii v czelyakh usileniya otvetstvennosti za prestupleniya seksual’nogo kharaktera, sovershenny`e v otnoshenii nesovershennoletnikh» // https://rg.ru/2012/03/02/neswovershennoletnye-dok.html

7. Ugolovny j kodeks RSFSR ot 27 oktyabrya $1960 \mathrm{~g}$. (UK RSFSR) (s izmeneniyami i dopolneniyami) (utratil silu) // https://base.garant.ru/10107062/

8. Svinkin A.I., Yushkov Yu.N. Osobo opasny j reczidiv kak kvalificziruyushhij priznak prestupleniya // Izvestiya vy`sshikh uchebny`kh zavedenij. Pravovedenie. - 1975. - \# 5. - S.92-100 // https://www.elibrary.ru/item.asp?id=24218252

9. Ugolovnoe delo \# 10-432/2020 // Arkhiv Chelyabinskogo oblastnogo suda.

10. Ugolovnoe delo \# 10-4857/2020 // Arkhiv Chelyabinskogo oblastnogo suda.

11. Ugolovnoe delo \# 10-1408/2019 // Arkhiv Chelyabinskogo oblastnogo suda.

12. Ugolovnoe delo \# 10-1694/2019 // Arkhiv Chelyabinskogo oblastnogo suda.

13. Ugolovnoe delo \# 10-4862/2016 // Arkhiv Chelyabinskogo oblastnogo suda.

БЕЛЯЕВА Ирина Михайловна, кандидат юридических наук, доцент, заведующий кафедрой уголовного и уголовно-исполнительного права, криминологии, Южно-Уральский государственный университет (национальный исследовательский университет). 454080, г. Челябинск, пр. им. В.И. Ленина, 76. E-mail: beliaevaim@susu.ru.

ЗУБЕНКО Игорь Анатольевич, доцент кафедры уголовного и уголовно-исполнительного права, криминологии, Южно-Уральский государственный университет, Южно-Уральский государственный университет (национальный исследовательский университет). 454080, г. Челябинск, пр. им. В.И. Ленина, 76. E-mail: zubenkoia@susu.ru.

BELYAEVA Irina Mikhailovna, Candidate of Sciences (Law), associate, Head Professor of Department of Criminal and Penal Enforcement Law, Criminology, South Ural State University (National Research University). 454080, Chelyabinsk, V.I. Lenin Ave., 76. E-mail: beliaevaim@susu.ru.

ZUBENKO Igor Anatolievich, Associate Professor of the Department of Criminal and Penal Enforcement Law, Criminology, South Ural State University, South Ural State University (National Research University). 454080, Chelyabinsk, V.I. Lenin Ave., 76. E-mail: zubenkoia@susu.ru. 